\title{
Role of neuromedin B and its receptor in the innate immune responses against influenza $A$ virus infection in vitro and in vivo
}

\author{
Guihong Yang ${ }^{*}{ }^{\circledR}$, Huipeng Huang ${ }^{\dagger}$, Mengyao Tang $^{\dagger}$, Zifeng Cai, Cuiqin Huang, Baomin Qi and Ji-Long Chen
}

\begin{abstract}
The peptide neuromedin B (NMB) and its receptor (NMBR) represent a system (NMB/NMBR) of neuromodulation. Here, it was demonstrated that the expression of NMBR in cells or murine lung tissues was clearly upregulated in response to H1N1/PR8 influenza A virus infection. Furthermore, the in vitro and in vivo activities of NMB/NMBR during PR8 infection were investigated. It was observed that A549 cells lacking endogenous NMBR were more susceptible to virus infection than control cells, as evidenced by the increased virus production in the cells. Interestingly, a significant decrease in IFN- $a$ and increased IL-6 expression were observed in these cells. The role of this system in innate immunity against PR8 infection was probed by treating mice with NMB. The NMB-treated mice were less susceptible to virus challenge, as evidenced by increased survival, increased body weight, and decreased viral NP expression compared with the control animals. Additionally, the results showed that exogenous NMB not only enhanced IFN-a expression but also appeared to inhibit the expression of NP and IL-6 in PR8-infected cells and animals. As expected, opposing effects were observed in the NMBR antagonist-treated cells and mice, which further confirmed the effects of NMB. Together, these data suggest that NMB/NMBR may be an important component of the host defence against influenza A virus infection. Thus, these proteins may serve as promising candidates for the development of novel antiviral drugs.
\end{abstract}

\section{Introduction}

Influenza A viruses (IAVs) invade the respiratory tract, causing direct damage via viral replication and indirect damage via the host's excessive defensive, production of inflammatory cytokines, called the cytokine storm [1]. Cytokine dysregulation contributes to the pathogenesis of H1N1, H5N1 and H7N9 viruses [2, 3] by inducing an imbalance in the host regulatory network, which results in severe complications and ultimately high mortality rates $[4,5]$. The most important methods for preventing and controlling IAV are antiviral treatments and annual vaccination. However, IAV antigens can mutate rapidly

\footnotetext{
*Correspondence: 877813797@qq.com; chenj|@im.ac.cn

${ }^{\dagger}$ Guihong Yang, Huipeng Huang and Mengyao Tang contributed equally to this work

Key laboratory of Fujian-Taiwan Animal Pathogen Biology, College

of Animal Sciences, Fujian Agricultural and Forestry University,

Fujian 350002, China
}

through the processes of antigenic drift and antigenic shift. As a result, drug-resistant viruses are continually emerging [6]. Over time, drug-resistant subtypes of IAV have been observed to escape the actions of antiviral drugs [7, 8]. Several drugs, such as amantadine and rimantadine, have been withdrawn from the market as a result of their reduced efficacy [9-12]. Currently, available antiviral drugs have several disadvantages: many negative side effects $[13,14]$, increased drug resistance, and single-target modes of action $[7,9,10,13,15]$. Thus, antiinfluenza drug development has increasingly focussed on host immunoregulation [16]. In response to viral infection, rapid induction of cytokines, including type I interferon $(\operatorname{IFN}-\alpha / \beta)$, is central to the establishment of innate antiviral immunity $[17,18]$. It has been demonstrated that neuroendocrine molecules are capable of regulating cytokine responses through auto- or self-secretions [19]. Therefore, neuroendocrine molecules may serve 
as promising candidates for the development of novel and potent antiviral drugs. Such members include neuromedin $\mathrm{B}(\mathrm{NMB})$, neuromedin $\mathrm{U}$, and neuropeptide $\mathrm{S}$. In particular, $\mathrm{NMB}$ has been shown to directly regulate IL-6 expression in tissues as well as its secretion into the serum of animals [20,21]. Therefore, the potential antiviral efficacy of NMB warrants further investigation.

To date, few reports have evaluated the role of NMB and NMBR in the process of IAV infection in animals. To this end, the potential anti-influenza activity of NMB and its receptor NMBR were examined here. Since it is very difficult to obtain natural NMB, the NMB used here was chemically synthesized. Additionally, a synthetic NMBR antagonist (NMBRA) was employed. First, NMB and NMBR expression was measured in PR8-infected cells and animals. Next, cells with a stable knockdown of NMBR were generated to assess its role in the host responses to IAV infection. NMBR-knockdown cells were more susceptible to PR8 infection than control cells. In addition, the effects of NMB and NMBRA treatment on PR8 infection both in vitro and in vivo were determined, which provided initial evidence that NMB and NMBR exert anti-H1N1 IAV effects.

\section{Materials and methods}

\section{Animals and ethics statement}

Specific pathogen-free (SPF) C57BL/6J mice at an age range of 5-6 weeks used in the present study were obtained from the WUSHI animal centre (Shanghai, China). The animals were housed in sterile cages under laminar airflow hoods in a SPF room with a $12 \mathrm{~h}: 12 \mathrm{~h}$ light-dark schedule. Animals were provided autoclaved feed and water ad libitum. This study was carried out in strict accordance with the Regulations for the Administration of Affairs Concerning Experimental Animals approved by the State Council of China. The study protocol was approved by the Research Ethics Committee of the College of Animal Science, Fujian Agriculture and Forestry University, under Permit Number PZCASFAFU2014002. All surgeries were performed under ether anaesthesia to minimize suffering and discomfort as much as possible. All animals received humane care in compliance with the university's guidelines.

\section{Virus, cell lines and peptides}

Influenza virus strain A/Puerto Rico/8/1934 (H1N1) (hereafter referred to as PR8) was propagated in SPF chicken embryos as previously described [22]. Viruses were then harvested and preserved at $-80{ }^{\circ} \mathrm{C}$ prior to use. Virus titres were determined using a standard plaque-forming unit (PFU) assay in MDCK cells. The titre of the virus stock obtained was $6.5 \times 10^{6} \mathrm{PFU} / \mathrm{mL}$.
The 293T, A549 and MDCK cells used in the present study were purchased from American Type Culture Collection. Cells were cultured at $37^{\circ} \mathrm{C}$ with $5 \% \mathrm{CO}_{2}$ in Dulbecco's modified Eagle's medium (DMEM) supplemented with $10 \%(\mathrm{v} / \mathrm{v})$ foetal bovine serum (FBS) (Gibco, US), 100 units of penicillin $\mathrm{G}$, and $100 \mu \mathrm{g}$ of streptomycin.

The NMB peptide and NMBR antagonist (NMBRA) were synthesized by manual solid-phase synthesis using standard Fmoc chemistry as previously described [23]. Synthetic NMB and NMBRA were dissolved in a $0.9 \%$ $\mathrm{NaCl}$ solution at doses of $1 \mathrm{nM}$ and stored at $-20{ }^{\circ} \mathrm{C}$ until use. The doses used here were selected based on a previous report [24] in addition to our own previous experiments.

\section{shRNA-based knockdown of NMBR and generation of cell lines}

Short hairpin RNA (shRNA)-based knockdown cell lines were generated by transfection of A549 cells with lentiviral vectors expressing specific shRNAs in a previously described pSIH-H1-GFP vector [22]. Sequences for NMBR shRNA were designed using Invivogen's online shRNA wizard. The shRNA targeting the NMBR gene (NMBR-shRNA), 5'-GGCAATTGCATGATTGACTCA$3^{\prime}$, was designed. A control shRNA targeting the luciferase gene (NC-shRNA), 5'-CTTACGCTGAGTACT TCGA-3', was used. The oligonucleotide duplex for each target was cloned into the pSIH-H1-GFP shRNA expression vector. Plasmids expressing NC- and NMBR-shRNA were cloned. Stable A549 cells expressing NMBR-shRNA (sh-NMBR cells) or NC-shRNA (sh-Luciferase cells) were generated using viral spin infection as described previously [25]. The above vector expresses GFP under the control of the CMV promoter to allow monitoring of transfection efficiency. To measure the knockdown efficiency, RT-PCR, quantitative RT-PCR (qRT-PCR) and Western blotting were performed.

\section{Isolation of murine bone marrow-derived macrophages (BMDMs)}

Primary BMDMs were isolated as previously described [26]. Both femurs were dissected, and bone marrow was flushed out from the medullary cavities with Dulbecco's phosphate-buffered saline containing $1 \times$ penicillin/streptomycin. Cells were centrifuged for $10 \mathrm{~min}$ at $1200 \mathrm{rpm}$ at room temperature and then resuspended in complete medium (DMEM supplemented with $10 \%$ FBS (v/v), $1 \%$ penicillin/streptomycin, and $50 \mathrm{ng} / \mathrm{mL}$ M-CSF (recombinant murine M-CSF, RP-8615, Invitrogen Inc., USA)). The cells were cultured at $37{ }^{\circ} \mathrm{C}$ under $5 \% \mathrm{CO}_{2}$ for 5 days with complete medium that was changed twice weekly. Approximately $5 \times 10^{6}$ BMDMs were obtained 
from each mouse. The viability of BMDMs was $>95 \%$, as confirmed by trypan blue exclusion staining.

\section{Virus infection and treatment in vitro}

In vitro infection of cells with the PR8 virus was performed under biosafety level 2 (BSL-2) laboratory conditions. 293T, A549, sh-NMBR, sh-Luciferase and BMDM cells were seeded in 6-well plates at $37{ }^{\circ} \mathrm{C}$ in $5 \%$ $\mathrm{CO}_{2}$. When the cells grew to a density of approximately 80-90\% confluence, the cells were infected with PR8 at the indicated multiplicity of infection (MOI) with genthe agitation every $15 \mathrm{~min}$. After adsorption at $37{ }^{\circ} \mathrm{C}$ for $1 \mathrm{~h}$, the cells were washed with phosphate-buffered saline (PBS) and cultured in DMEM containing $2 \mu \mathrm{g} / \mathrm{mL}$ trypsin (Sigma-Aldrich). 293T and A549 cells were harvested at $0,3,6,9$, and $12 \mathrm{~h}$ post-infection (hpi) for NMB and NMBR expression analysis by RT-PCR and qRT-PCR. The sh-NMBR cells and sh-Luciferase cells were harvested at either 0,6 , or $12 \mathrm{hpi}$ for gene expression analysis by RT-PCR and qRT-PCR and protein expression by WB. Supernatants of sh-NMBR cells and sh-Luciferase cells were harvested at 12, 24, 36, 48 and 64 hpi for virus titration. The viral titres were determined by plaque assay.

One hour after infection with PR8, the BMDMs and A549 cells were incubated with either $1 \mathrm{nM}$ NMB or NMBR antagonist (NMBRA) and cultured at $37{ }^{\circ} \mathrm{C}$ in $5 \%$ $\mathrm{CO}_{2}$. Meanwhile, the mock-treated cells were incubated with DMEM without NMB or NMBRA. Cells were harvested at 16 hpi for gene expression analysis by RT-PCR and qRT-PCR.

\section{Infection of mice and treatments}

Six groups of mice were set up: group 1 (PR8-Mock), group 2 (PR8-NMB +), group 3 (PR8-NMBRA+), group 4 (PR8+Mock), group 5 (PR8 $+\mathrm{NMB}+$ ), and group 6 $(\mathrm{PR} 8+\mathrm{NMBRA}+)$. Each group contained twenty-five mice, with each mouse having a mass of approximately 20-22 g. For this experimental setting, the animals in groups 1, 2, and 3 were mock-treated with $100 \mu \mathrm{L}$ SPF chick embryo allantoic fluid, and the animals in groups 4,5 , and 6 were anaesthetized and inoculated intranasally with $6.5 \times 10^{4}$ PFU of PR8 virus. On the day after infection, the animals in groups 1 and 4 were mock-treated with $100 \mu \mathrm{L} 0.9 \% \mathrm{NaCl}$ solution. Simultaneously, the animals in groups 2 and 5 were injected with $1 \mathrm{nM}$ NMB in a volume of $100 \mu \mathrm{L}$, and the animals in groups 3 and 6 received $100 \mu \mathrm{L} 1 \mathrm{nM}$ NMBRA. All mice were monitored daily for signs of flaccid paralysis, and any deaths were recorded. Ten mice from each group were euthanized on $3 \mathrm{dpi}$, from which lung samples were collected and immediately flash-frozen in liquid nitrogen and then stored at $-80{ }^{\circ} \mathrm{C}$ until future RNA extraction. All other animals in each group were monitored daily for up to 10 days.
Table 1 Primers used for RT-PCR and qRT-PCR in mouse tissue

\begin{tabular}{|c|c|c|}
\hline Primer names & GenBank accession no. & Sequence $\left(5^{\prime}-3^{\prime}\right)$ \\
\hline NMB sense & NM_001291280.1 & CGGTCACTTCATGGGCAAG \\
\hline NMB antisense & & $\begin{array}{l}\text { GAGCTTTCTTTCGCAGGA } \\
\text { GGA }\end{array}$ \\
\hline NMBR sense & NM_008703.3 & $\begin{array}{l}\text { CATGCGGAATGTCCCTAA } \\
\text { CATC }\end{array}$ \\
\hline NMBR antisense & & $\begin{array}{l}\text { CCAAGCTACCAATGCGTG } \\
\text { CTAC }\end{array}$ \\
\hline$\beta$-actin sense & NM_007393.5 & $\begin{array}{l}\text { AATGGGTCAGAAGGA } \\
\text { CTCCT }\end{array}$ \\
\hline$\beta$-actin antisense & & $\begin{array}{l}\text { ACGGTTGGCCTTAGGGTT } \\
\text { CAG }\end{array}$ \\
\hline IL-6 sense & NM_001314054.1 & TTGCCTTCTTGGGACTGATG \\
\hline IL-6 antisense & & TCTGGCTTTGTCTTTCTTGT \\
\hline IFN-a sense & NM_206871.2 & $\begin{array}{l}\text { TCCTGCCTGAAGGACAGG } \\
\text { AAGG }\end{array}$ \\
\hline IFN- $\alpha$ antisense & & $\begin{array}{l}\text { AGGGCTCTCCAGACTTCT } \\
\text { GCTCTG }\end{array}$ \\
\hline NP sense & CY034135.1 & TCAAACGTGGGATCAATG \\
\hline NP antisense & & GTGCAGACCGTGCTAAAA \\
\hline
\end{tabular}

The primers designed for the NP gene listed in this table could also be used in human tissues after virus infection.

\section{RT-PCR and qRT-PCR}

Total RNA was extracted from PR8-infected and control cells at the indicated time points. In addition, RNA was extracted from mouse lung tissues at $3 \mathrm{dpi}$ using Trizol (TIANGEN Biotech, China) according to the manufacturer's instructions. Equal amounts of RNA $(2 \mu \mathrm{g})$ were reverse transcribed into cDNA utilizing M-MLV Reverse Transcriptase (Promega, USA). The cDNA was analysed by qRT-PCR using the TransStart Green qPCR SuperMix (TransGen Biotech, China) and RT-PCR using rTaq DNA polymerase (Takara Bio, Japan). Human $\beta$-actin and glyceraldehyde-3-phosphate dehydrogenase (GAPDH) were used as references for internal standardization. Amplicons from the PCRs were separated on a 1.5\% agarose gel, which was stained with nucleic acid stain I (Roche Diagnostics, Mannheim, Germany), photographed, and analysed using the Gene Tools Analysis Software (Syngene, Cambridge, UK). The qRT-PCR data are presented as normalized ratios, which were calculated using the $\Delta \Delta C T$ method with the LightCycler system and software (Roche, Switzerland). All primers used for RT-PCR and qRT-PCR are presented in Tables 1 and 2.

\section{Western blotting}

Lung tissue lysates from the mice were prepared from tissues collected at 3 dpi. Lysates of sh-NMBR cells, shLuciferase cells, PR8-infected sh-NMBR cells, and noninfected controls were prepared from samples harvested 
Table 2 Primers used for RT-PCR and qRT-PCR in human cells

\begin{tabular}{|c|c|c|}
\hline Primer names & GenBank accession no. & Sequence $\left(5^{\prime}-3^{\prime}\right)$ \\
\hline NMB sense & NM_021077.4 & $\begin{array}{l}\text { TAAAGAAGGCTCTGG } \\
\text { GCGTG }\end{array}$ \\
\hline NMB antisense & & $\begin{array}{l}\text { GGTGACCCAGCCAGA } \\
\text { AATCA }\end{array}$ \\
\hline NMBR sense & NM_002511.3 & $\begin{array}{l}\text { ACCTAAATCGTGGGC } \\
\text { GTTCA }\end{array}$ \\
\hline NMBR antisense & & $\begin{array}{l}\text { GGCAGGAAATCCCTT } \\
\text { TCCCA }\end{array}$ \\
\hline GAPDH sense & NM_002046.7 & $\begin{array}{l}\text { TGGGTGTGAACCATG } \\
\text { AGAAGT }\end{array}$ \\
\hline GAPDH antisense & & $\begin{array}{l}\text { AAGGCCATGCCAGTG } \\
\text { AGCTT }\end{array}$ \\
\hline IL-6 sense & NM_000600.5 & $\begin{array}{l}\text { ACAAATTCGGTACATCCT } \\
\text { CGAC }\end{array}$ \\
\hline IL-6 antisense & & $\begin{array}{l}\text { TGGCTTGTTCCTCAC } \\
\text { TACTCT }\end{array}$ \\
\hline IFN-a sense & J00210.1 & $\begin{array}{l}\text { TGATCTGCCTCAAAC } \\
\text { CCACA }\end{array}$ \\
\hline IFN- $a$ antisense & & $\begin{array}{l}\text { ATCTGCTGGATCATCTCA } \\
\text { TGG }\end{array}$ \\
\hline
\end{tabular}

at 0,6 , and $12 \mathrm{hpi}$. All lysates were resolved by SDSPAGE in $10 \%$ polyacrylamide gels. Bands were detected using rabbit anti-H1N1-NP (generated in our laboratory) as previously described [27] and anti-hNMBR (ab134141, Abcam, USA). $\beta$-Actin was detected using a rabbit antiactin polyclonal antibody (R019, TransGen Biotech, China). The secondary antibodies for detection were goat anti-mouse (125229, Jackson ImmunoResearch Laboratories, USA) and goat anti-rabbit antibodies (131879, Jackson ImmunoResearch Laboratories). The blots were developed using the FluorChem M Imaging System (ProteinSimple, USA).

\section{Plaque assay}

The supernatant was diluted with medium and added to MDCK cell monolayers in 6-well plates. After $1 \mathrm{~h}$ of incubation in $5 \% \mathrm{CO}_{2}$ at $37{ }^{\circ} \mathrm{C}$, the supernatant was removed, and the covering medium containing 1.5\% lowmelting-point agarose (Promega, Madison, WI, USA) was then overlaid on the cells. After coagulation of agarose, the maintenance medium was added, and the plates were further incubated for 3 days for plaque formation. Next, the cells were fixed with $10 \%$ formalin overnight and stained with crystal violet $(1 \% \mathrm{~W} / \mathrm{V})$ for $30 \mathrm{~min}$. The number of plaques was counted.

\section{Statistical analysis}

Survival curves were analysed using the log-rank test (GraphPad Prism5). Other data are presented as mean \pm SEM. Differences were considered significant when $P \leq 0.05$. Statistical analysis was completed by oneway ANOVA using SPSS 16.0 (Chicago, IL, USA).

\section{Results \\ Expression of NMB and NMBR is upregulated in 293T and A549 cells following PR8 infection}

To determine the role of $\mathrm{NMB}$ and its receptor, NMBR, in the host antiviral response to IAV infection, the expression of NMB and NMBR was analysed in 293T and A549 cells at $0,3,6,9$, and $12 \mathrm{hpi}$. The expression levels of both NMB and NMBR were very low in the mock-treated controls (0 hpi). The expression level of NMB was slightly increased, whereas the expression of NMBR was clearly increased, in 293T cells in response to virus infection (Figure 1A). Consistent with that, the results from qRTPCR showed that the expression of NMB mRNA was significantly increased at $12 \mathrm{hpi}$ (Figure $1 \mathrm{~B}$ ), and expression of NMBR mRNA was significantly increased at 6 , 9, and 12 hpi (Figure 1C). Similar profiles of both NMB and NMBR expression following infection with PR8 were also observed in A549 cells (Figures 1D-F). To determine whether trypsin addition had any side effects during PR8 infection, the expression of IL- 6 and protease-activated receptors 2 (PAR2) was investigated. It was observed that trypsin had no significant effect on IL-6 mRNA or PAR2 protein level in response to PR8 infection (Additional file 1). These results indicated that PR8 infection can significantly induce the expression of NMBR in host cells.

\section{PR8 infection increases NMB and NMBR expression in vivo}

To better understand the potential roles of NMB and NMBR in the host innate immune response to IAV infection, mice were infected with PR8, and lung tissues of PR8-infected and non-infected control animals were collected at $3 \mathrm{dpi}$. The tissue-specific expression of NMB and NMBR mRNA was assessed by RT-PCR and qRT-PCR. Similarly to above, it was observed that the expression of NMB and NMBR increased in lung tissues following infection with PR8 (Figures 1G-I).

\section{Cells deficient in NMBR are more susceptible to PR8 infection}

To test the hypothesis that NMB/NMBR plays a role in the host defences against IAV infection, A549 cells deficient in NMBR were generated. The transfection efficiency of the shRNA expression plasmid vector used in this study, as determined by the proportion of GFP-positive cells, is presented in Figure 2A. To verify the efficacy of the shRNA-mediated knockdown of NMBR in A549 cells, the expression of NMBR mRNA in sh-Luciferase controls and sh-NMBR cells was examined by RT-PCR and qRT-PCR (Figures 2B, C), and protein expression 


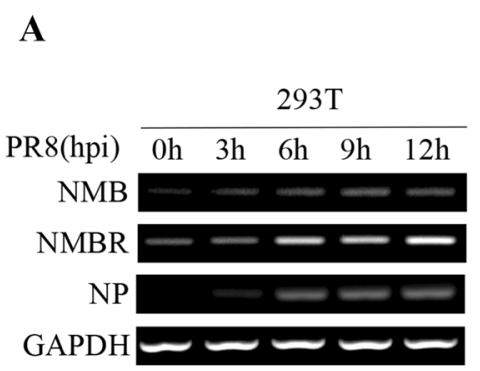

D

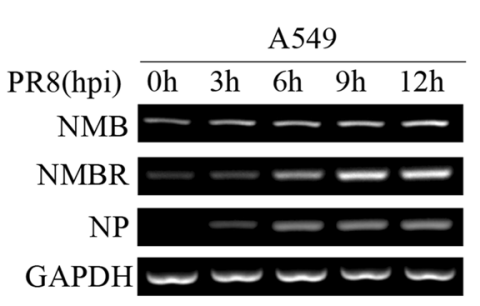

G

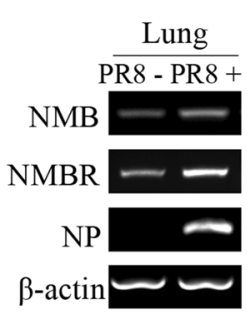

B

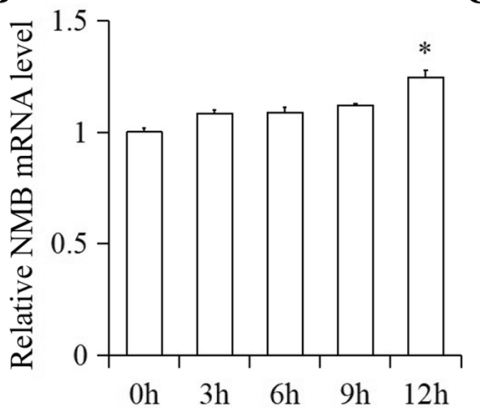

Hours post-infection (hpi)

E

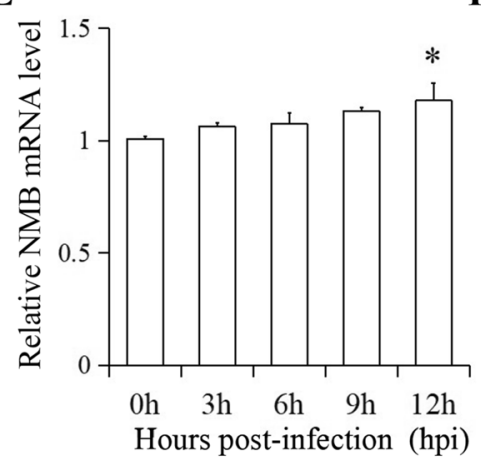

H

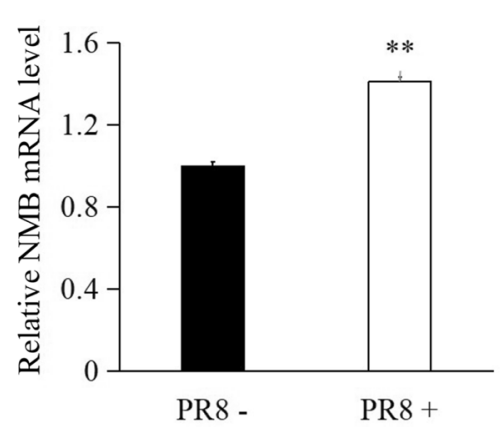

C

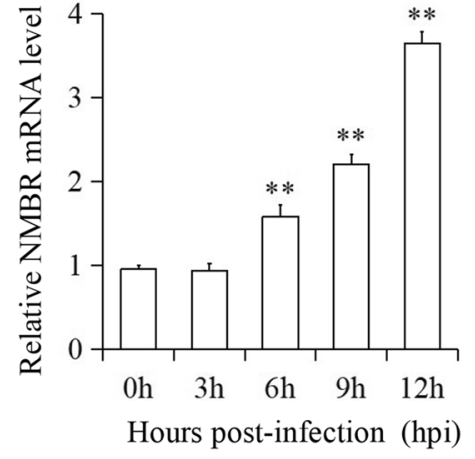

F

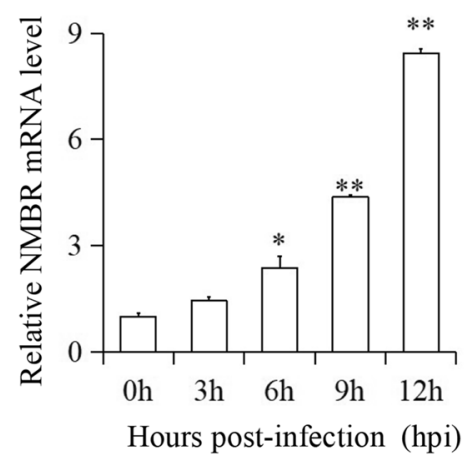

I

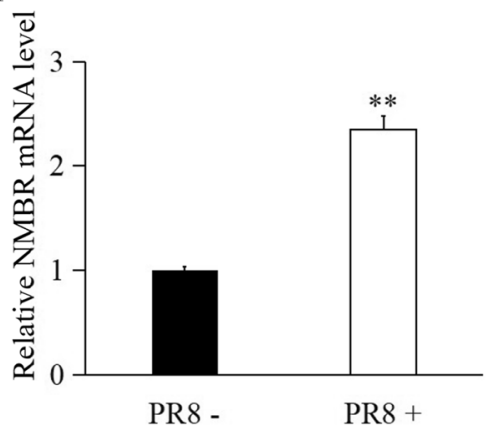

Figure 1 PR8 induction of NMB and NMBR expression. 293T and A549 cells were infected with PR8 $(\mathrm{MOI}=1)$ and harvested at 0,6, and 12 hpi, and lung tissues were harvested at 3 dpi, to measure the expression of NMB and NMBR by RT-PCR and qRT-PCR. A-C Expression of NMB and NMBR in 293 T cells. D-F Expression of NMB and NMBR in A549 cells. G-I NMB and NMBR expression in mouse lungs. GAPDH, glyceraldehyde-3-phosphate dehydrogenase; NP, virus nucleoprotein; $\beta$-actin or GAPDH were used as reference housekeeping genes for internal standardization. ${ }^{*} P<0.05$, **P $<0.01$.

was examined by Western blotting (Figure 2D). The data demonstrated that shRNA targeting of NMBR efficiently silenced the expression of NMBR in the A549 cell line.

Next, the sh-NMBR and sh-Luciferase control cells were infected with PR8 and harvested at 0,6 , and 12 hpi. NP expression was slightly enhanced in the NMBRdeficient cells compared to the mock-treated cells (Figure 3A). To confirm the reliability of these data, qRT-PCR was performed to measure the expression of NP, and a more significant result was obtained from this assay
(Figure 3B). Similarly, the Western blot results showed that the expression of NP was substantially upregulated in the NMBR-deficient cells (Figure 3C). In addition, virus replication in NMBR-deficient cells was higher than that of control cells in the plaque assay (Figure 3D). To demonstrate the potential impact of NMBR signalling on the host innate immune system, the expression of IFN- $\alpha$ and IL- 6 in the context of PR8 infection was assessed in sh-NMBR cells by RT-PCR. The data indicated a decrease in IFN- $\alpha$ expression, whereas the expression of IL- 6 was 

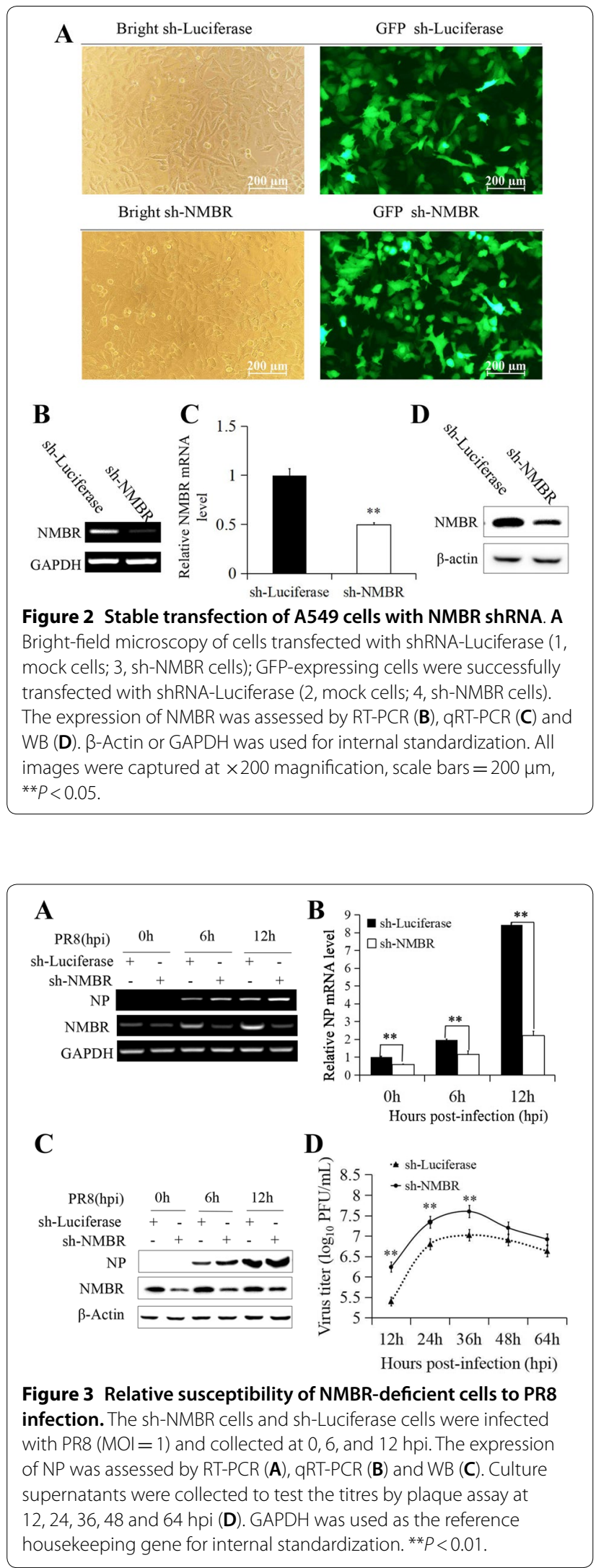

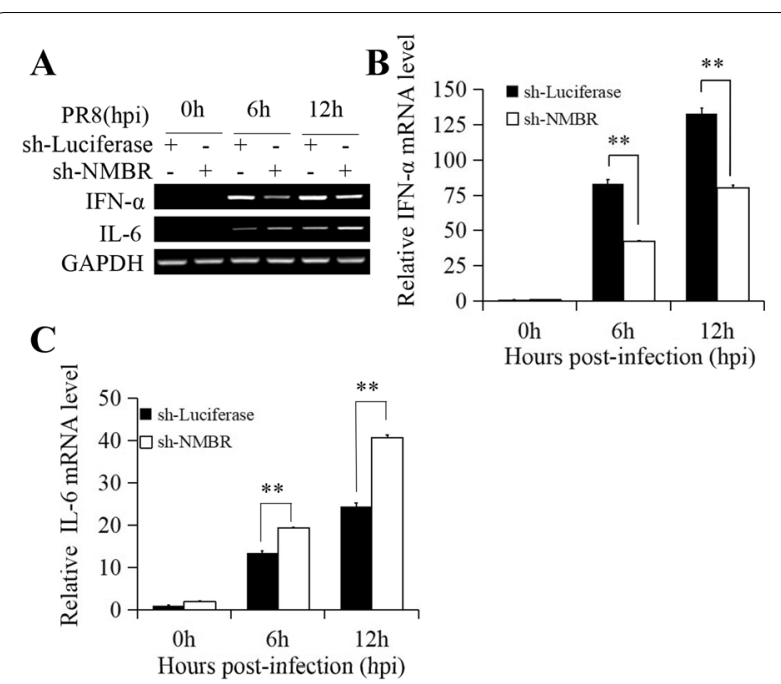

Figure 4 Cytokine expression in cells lacking NMBR after PR8 infection. The cells were infected with PR8 $(\mathrm{MOI}=1)$ and harvested to assay the expression of IFN- $a$ and IL-6 at 0, 6, and 12 hpi. A RT-PCR revealed a significant decrease in IFN-a expression and a significant increase in IL-6 expression in sh-NMBR cells compared to mock cells (sh-Luciferase cells); qRT-PCR confirmed the expression profile of $\mathbf{B}$ IFN- $a$ and $C I L-6 .{ }^{* *} P<0.01,{ }^{*} P<0.05$.

upregulated in these cells (Figure 4A). The observed gene expression profile of IFN- $\alpha$ and IL- 6 was further confirmed by qRT-PCR (Figures $4 \mathrm{~B}, \mathrm{C}$ ). Taken together, these data suggest that NMBR is an important component in the host innate defence against IAV infection.

\section{NMB/NMBR inhibits PR8 infection in vitro}

To determine the effect of NMB on PR8 infection, the effects of NMB and NMBRA on the expression of viral NP, IFN- $\alpha$ and IL- 6 were examined in A549 cells and BMDMs. NP expression was significantly reduced following NMB treatment in A549 cells (Figures 5A, B). Furthermore, treatment with $\mathrm{NMB}$ resulted in an upregulation of IFN- $\alpha$ (Figures $5 \mathrm{~A}, \mathrm{C}$ ) and downregulation of IL-6 expression (Figures 5A, D) in PR8-infected A549 cells. Indeed, viral NP expression was increased in A549 cells treated with $1 \mathrm{nM}$ NMBRA (Figures 6A, B). The expression of IFN- $\alpha$ in A549 cells was markedly downregulated (Figures 6A, C), and IL-6 was upregulated (Figures 6A, D) by NMBRA treatment after PR8 infection. In BMDMs, similar expression levels of NP, IFN- $\alpha$ and IL- 6 mRNA induced by NMB treatment or NMBRA treatment were observed in BMDMs after PR8 infection (Additional files 2,3). Thus, the expression profile of these genes in the presence of NMBRA was in contrast to that of NMB-treated cells. Meanwhile, the expression of IL- 6 mRNA and PAR2 in BMDMs and the expression of NMBR in A549 cells and BMDMs were not affected 


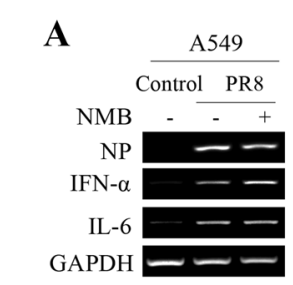

$$
\text { B }
$$

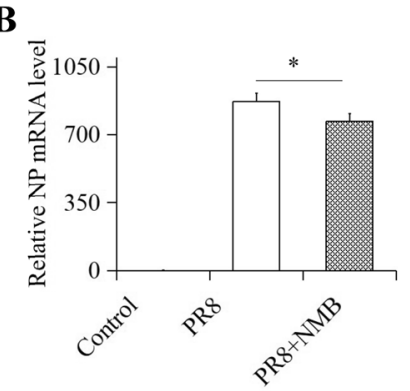

C

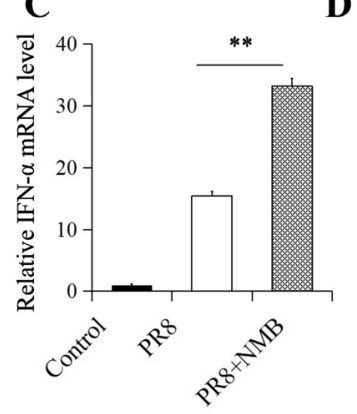

D

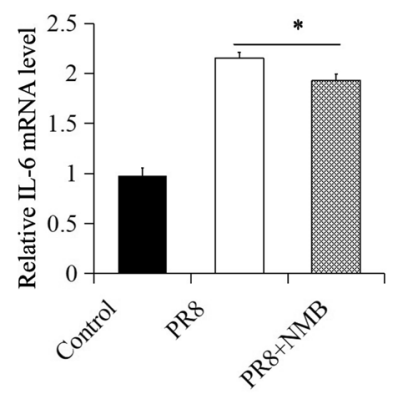

Figure 5 Effect of NMB treatment on the expression of viral NP and cytokines in A549 cells. The A549 cells were mock-treated or treated with $\mathrm{NMB}$ after infection with PR8 $(\mathrm{MOI}=1)$. NMB-treated cells were harvested at $16 \mathrm{hpi}$. A The mRNA levels of NP, IFN-a, and IL-6 were measured by RT-PCR. qRT-PCR measurement of NP (B), IFN- $a(\mathbf{C})$ and IL-6 (D) mRNA expression. GAPDH was used as the reference housekeeping gene for internal standardization. ${ }^{* *} P<0.01$, ${ }^{*} P<0.05$.

by trypsin during PR8 infection (Additional file 4), suggesting that trypsin is not involved in the effects of NMB and NMBRA treatments in PR8-infected cells. Together, the results reveal that NMB/NMBR induced a substantial increase in IFN- $\alpha$ and a significant decrease in IL-6 expression in response to PR8 infection.

\section{NMB/NMBR exhibits anti-influenza virus activity in vivo}

To investigate the anti-IAV activity of NMB/NMBR in vivo, mice were infected with PR8 and then injected with NMB, NMBRA, or mock control. As expected, PR8 challenge resulted in clinical signs consistent with PR8 infection in mice at $3 \mathrm{dpi}$ (Figure 7A). However, the clinical signs were markedly less severe in animals treated with NMB and were exacerbated in the NMBRA-treated group (Figure 7A). To further determine the effects of NMB or NMBRA in vivo, mortality rates were compared between the groups over the 10-day period following PR8 challenge. As can be seen in Figure 7B, the control mice began to die by $4 \mathrm{dpi}$, and all mice succumbed by $5 \mathrm{dpi}$. However, mortality was reduced to $50 \%$ in the NMBtreated mice. Similar to the infection control group, all mice died in the NMBRA treatment group within 4.5 days
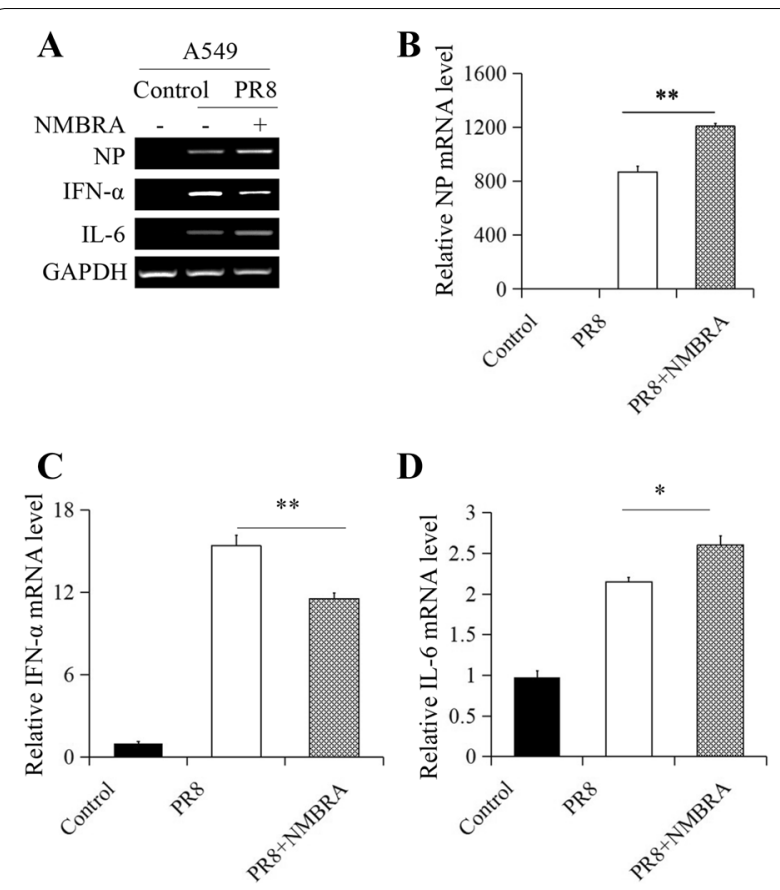

Figure 6 Effect of NMBRA treatment on the expression of viral NP and cytokines in A549 cells. The A549 cells were mock-treated or treated with NMBRA after infection with PR8 $(\mathrm{MOI}=1)$.

NMBRA-treated cells were harvested at $16 \mathrm{hpi}$. A The mRNA levels of NP, IFN- $a$, and IL- 6 were measured by RT-PCR. The expression of NP (B), IFN-a (C), and IL-6 (D) were measured by qRT-PCR. GAPDH was used as the reference housekeeping gene for internal standardization. ${ }^{*} P<0.01,{ }^{*} P<0.05$

after infection. Notably, all mice in the mock group survived the duration of the experiment. As presented in Figure $7 \mathrm{C}$, the weight gain of all mice increased steadily in the three PR8-negative groups. Mice infected with PR8 exhibited a precipitous weight loss after 1 day, decreasing to less than $75 \%$ after 5 days. Mice infected with PR8 and treated with NMBRA lost weight faster than the PR8 infection-alone group. Interestingly, mice treated with NMB after virus challenge exhibited a steady weight gain after 7 days of continual weight loss. Consistent with the data from the above in vitro experiments, the lung tissues were sampled for analysis of viral NP expression, and NMB treatment resulted in a downregulation of NP expression following PR8 infection (Figures 8A, B). Analysis of protein expression by Western blotting confirmed that NMB treatment effectively inhibited the expression of NP protein in the lungs of mice infected with PR8 (Figure $8 \mathrm{C}$ ). Moreover, the expression profiles of viral NP mRNA and protein after treatment with NMBRA were also assessed by RT-PCR, qRT-PCR and Western blotting. The expression of NP in the NMBRA-treated animals was opposite to that observed in the NMB-treated group (Figures $8 \mathrm{D}-\mathrm{F}$ ). Taken together, these data suggest 
$\mathbf{A}$

PR8+MOCK

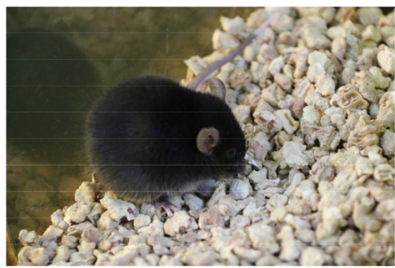

$\mathrm{PR} 8+\mathrm{NMB}+$

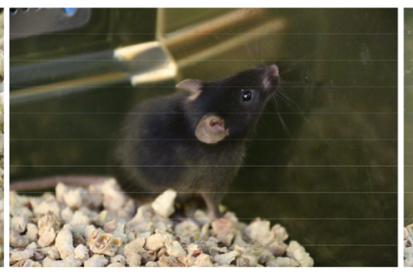

PR8+NMBRA+

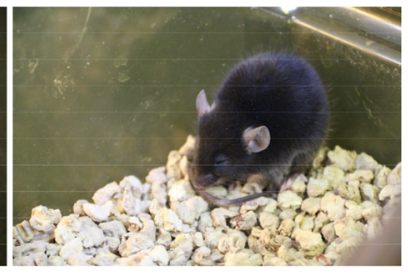

B

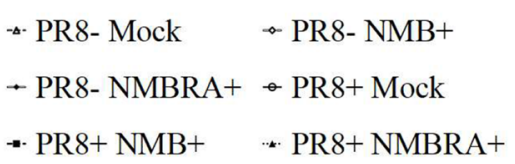

$\mathrm{C} \leadsto \mathrm{PR} 8-\mathrm{Mock} \rightarrow \mathrm{PR} 8-\mathrm{NMB}+$

+ PR8 - NMBRA $+\rightarrow$ PR8 + Mock

- PR8+ NMB+
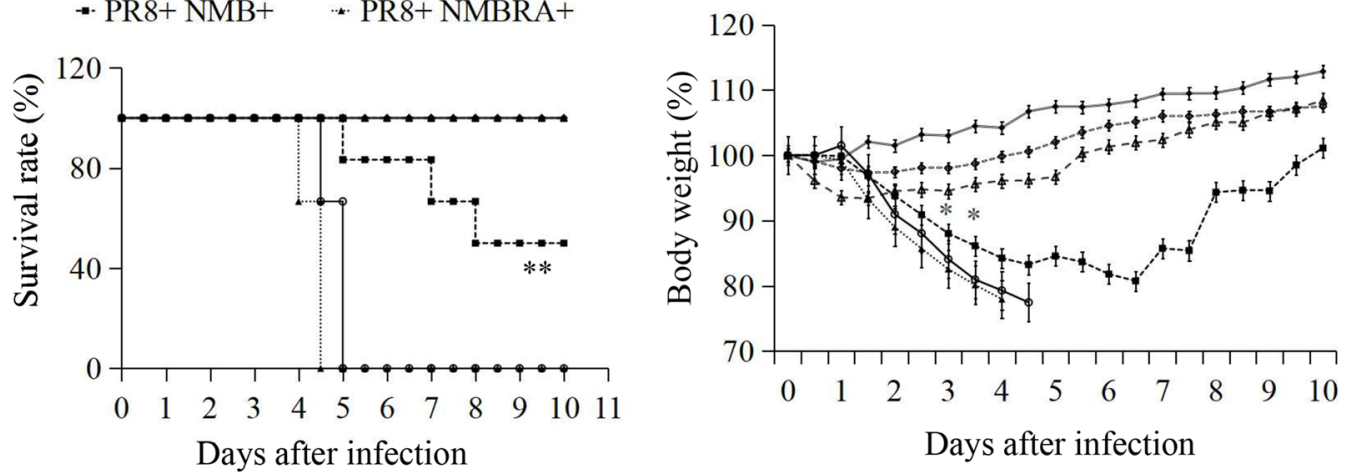

Figure 7 Effects of NMB and NMBRA treatment on virus replication in vivo. A Representative photographs of mock-treated mice infected with PR8, PR8-infected mice treated with $1 \mathrm{nM} \mathrm{NMB}$, and PR8-infected mice treated with $1 \mathrm{nM}$ NMBRA; $\mathbf{B}$ survival rates of mice in 6 treatment groups; $\mathbf{C}$ body weights of the 6 groups of mice. The mice were monitored for up to 10 days, and survival curves were compared using a log-rank test (GraphPad Prism 5). ${ }^{*} P<0.01,{ }^{*} P<0.05$.

that the expression of NMB could reduce the susceptibility of mice to PR8 infection.

Next, RT-PCR and qRT-PCR were used to determine the expression of IFN- $\alpha$ and IL- 6 in mice infected with PR8 alone or in the context of NMB or NMBRA treatment. The combination of PR8 infection and NMB treatment induced a significant increase in IFN- $\alpha$ expression (Figures 9A, B) and decreased IL-6 expression (Figures 9A, C). Specifically, RT-PCR and qRT-PCR analysis indicated that NMBRA treatment induced a substantial decrease in IFN- $\alpha$ and a significant increase in IL-6 expression (Figures 9D-F). Thus, the effects of NMBRA were in contrast to those of NMB in PR8-infected mice, as expected.

\section{Discussion}

A key member of the neuroendocrine system, NMB controls various exocrine and endocrine functions through signalling cascades upon binding to its receptor, NMBR $[20,28]$. Although research into the antiviral activity of this protein in mammals has not been thoroughly examined, it has been well characterized in the context of immune regulation [19]. However, the expression profiles of NMB and NMBR during IAV infection and the activity of NMB/NMBR in hosts during virus infection remain unclear. The present study reports, for the first time, the expression and activity of $\mathrm{NMB} / \mathrm{NMBR}$ in response to PR8 infection.

Interestingly, the upregulation of NMB and NMBR was detected after the virus challenge. A significant increase in NMBR expression was observed in the infected host. These data indicate that NMBR may be involved in the pathological or host defence processes of PR8/IAV infection. It is well known that many viruses are capable of modulating the expression of inflammatory cytokines (e.g., IL-6), thus allowing the virus to establish a successful infection [29-31]. Although it appears from the data presented here that induction of NMBR in response to IAV/PR8 infection is indeed part of the host innate response and is detrimental to the virus, further studies are necessary to confirm these findings.

Strikingly, the data presented here demonstrated that the disruption of NMBR signalling resulted in increased PR8 replication in vitro. This conclusion was supported by the fact that the depletion of NMBR increased the susceptibility of host cells to PR8 infection. Although the 

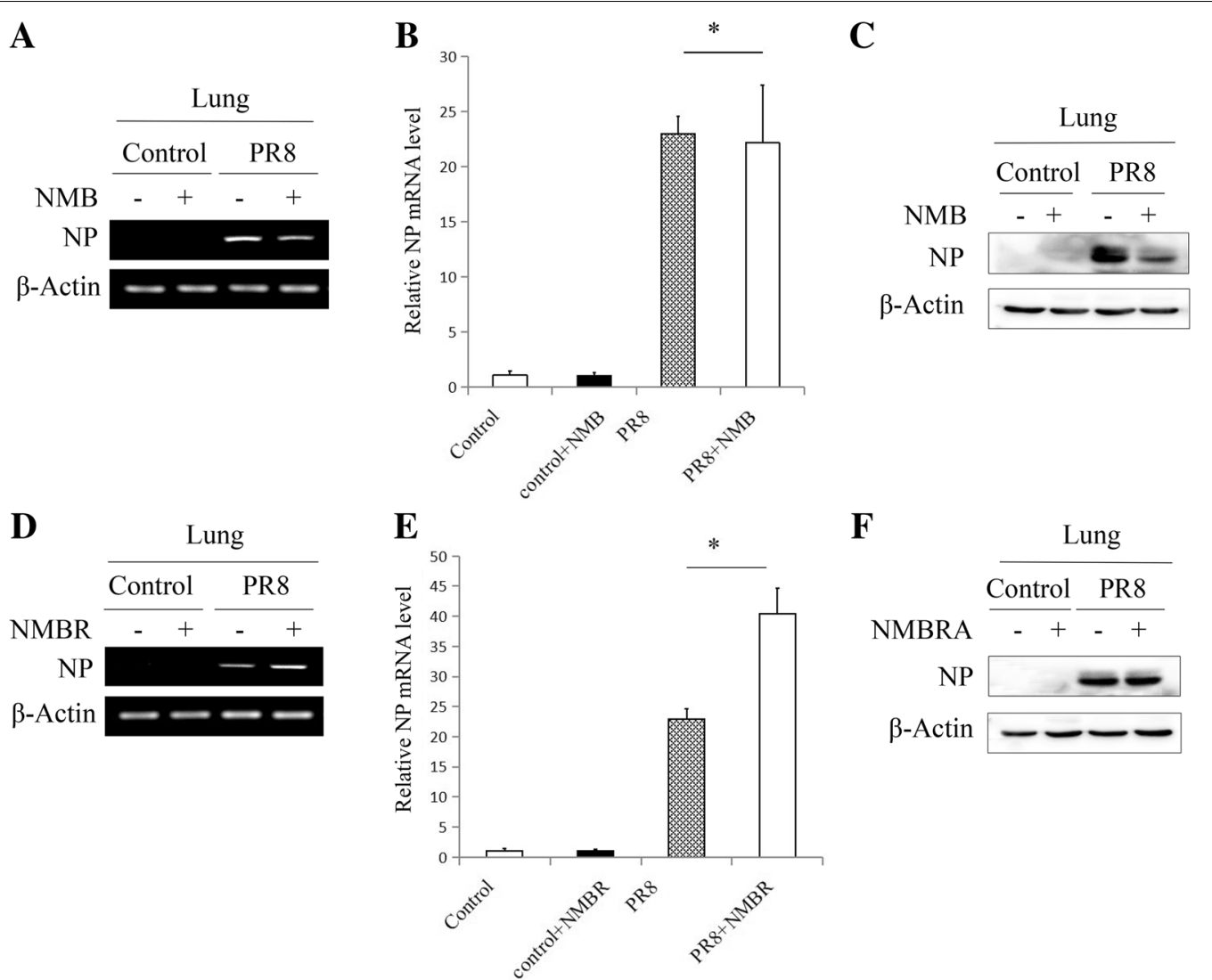

Figure 8 Effects of NMB and NMBRA treatments on the expression of virus NP in mice. Lung tissues from treated mice were sampled at 3 dpi. The profiles of NP expression were assayed by RT-PCR, qRT-PCR or Western blotting. Decreased virus NP expression after NMB treatment was observed (A-C); increased virus NP expression induced by NMBRA treatment was confirmed (D-F). $\beta$-Actin was used for internal standardization. $* P<0.05$.

roles of IFN- $\alpha$ are beneficial for the host following viral infection, the excessive production of IL-6 stimulated by IAV infection can result in pathogenic effects in the host organs, increasing the risk of severe disease and death $[32,33]$. Here, it was observed that the increased expression of IL- 6 and decreased expression of IFN- $\alpha$ were induced in NMBR-deficient cells in response to PR8 infection. It is very likely that the high expression level of IL- 6 and reduced IFN- $\alpha$ expression in cells lacking NMBR are contributing factors in the pathogenesis of PR8. Our results indicate that endogenous NMBR is an important part of the host defence against PR8 infection. Therefore, we hypothesized that the NMBR ligand, NMB, is a potential therapeutic agent for the treatment of PR8 infection.

To test the above hypothesis, the anti-influenza virus activity of NMB was examined both in vitro and in vivo. The data collected from all of the experiments that were conducted corroborated the hypothesis that NMB can inhibit IAV replication. As expected, NMB treatment reduced the clinical signs associated with PR8 infection.
These results suggest that NMB is an important factor in combating PR8 infection. However, the specific antiviral mechanisms of $\mathrm{NMB}$ remain unclear. In the present study, NMB suppressed the expression of IL-6 in PR8-infected cells and mice. Since IL-6 plays a vital role in the pathogenesis of H1N1 [34], this may, at least in part, explain the anti-PR8 effect of NMB. It has been established that there is cross-talk between IL- 6 signalling and IFN- $\alpha / \beta$ signalling [35-38]. The rapid induction of type I IFN is a critical step in the establishment of the innate antiviral response $[17,18]$. Consistent with this concept, NMB treatment reversed the expression profiles of IFN- $\alpha$ and IL- 6 induced by PR8 infection both in vitro and in vivo. Furthermore, when synthetic NMBRA was injected into mice after PR8 infection, the cytokine expression profiles reversed relative to those under $\mathrm{NMB}$ treatment, thus corroborating the observed antiviral activity of NMB. Therefore, it is likely that NMB plays an anti-inflammatory role via the regulation of the host type I IFN signalling pathway. Of course, the signalling pathway in which NMB participates requires further research. 


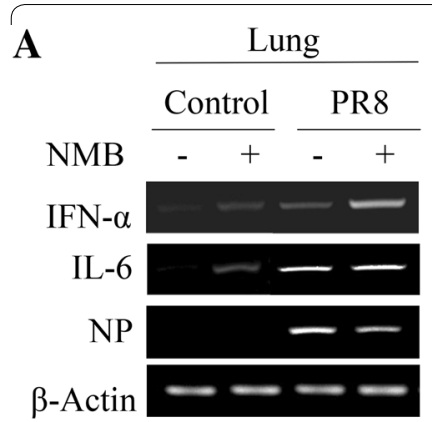

D

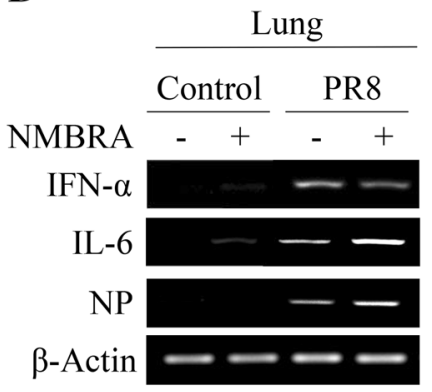

B

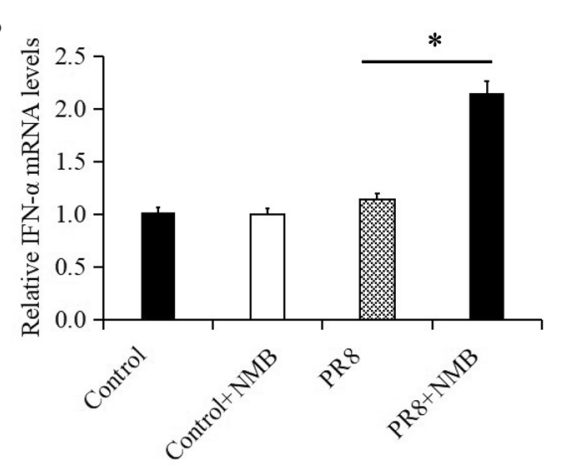

$\mathbf{E}$

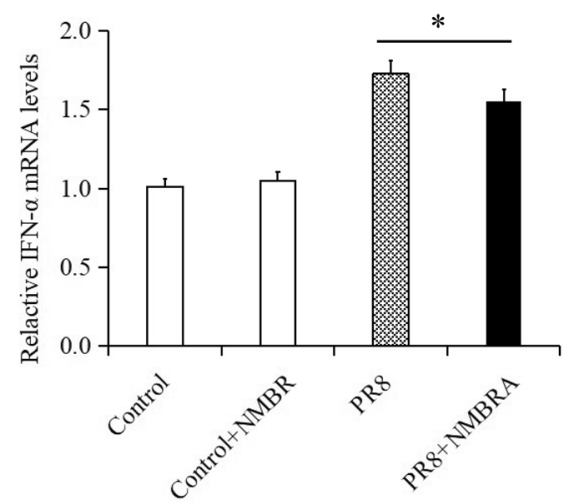

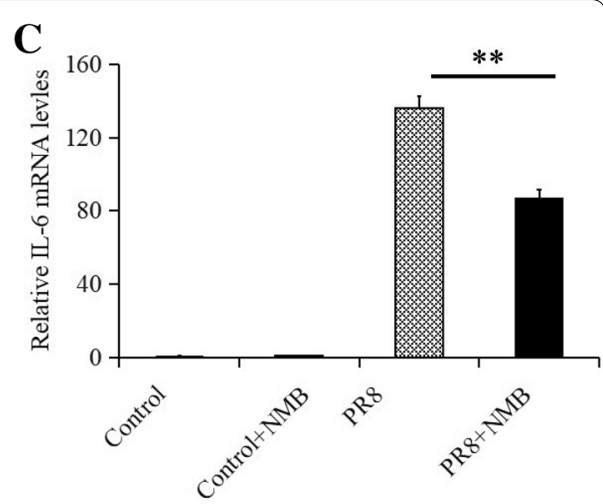

$\mathbf{F}$

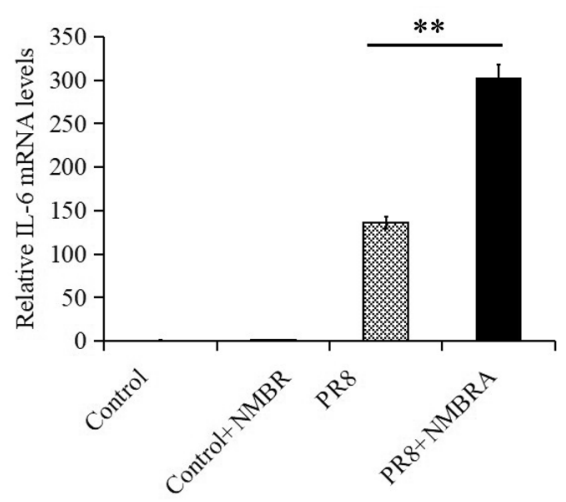

Figure 9 Effects of NMB and NMBRA treatment on the expression of cytokines in mice. Lung tissues from treated mice were sampled at 3 dpi. The expression patterns of IFN- $a$ and IL-6 in lung tissues were assessed using RT-PCR and QRT-PCR. NMB treatment induced the upregulation of IFN- $\alpha(\mathbf{A}, \mathbf{B})$ and downregulation of IL-6 (A, C); NMBRA treatment induced the downregulation of IFN- $\alpha(\mathbf{D}, \mathbf{E})$ and upregulation of IL-6 (D, F). $\beta$-Actin was used as the reference housekeeping gene for internal standardization ${ }^{*} P<0.05 ;{ }^{*} P<0.01$.

The present data represent the first demonstration of the in vitro and in vivo efficacy of NMB/NMBR against PR8 infection. Cells deficient in NMBR expression exhibited increased susceptibility to the influenza A virus. Furthermore, the NMB/NMBR system appeared to increase IFN- $\alpha$ expression and decrease IL- 6 expression after PR8 infection, which may serve to establish an antiviral state in the host. The effects observed following PR8 infection and NMBRA treatment further suggest an important role of NMB in antiviral immunity. However, the potential activity of NMB/NMBR against other viruses requires further research. These results provide a critical basis for the future therapeutic application of NMB/NMBR against IAV infection.

\section{Supplementary information}

Supplementary information accompanies this paper at https://doi. org/10.1186/s13567-019-0695-2.
Additional file 1. Effect of trypsin on the expression of IL-6 and PAR2 in cells. The 293T and A549 cells were infected with PR8 $(\mathrm{MOI}=1)$ in the presence or absence of trypsin. The 293T cells at 0,3 and $12 \mathrm{hpi}$ and A549 cells at $0,3,12$, and 16 hpi were collected to test the expression of IL- 6 mRNA in 293T and A549 cells by RT-PCR and GRT-PCR and the expression of PAR2 and NMBR in A549 cells by Western blotting. (A, B) IL-6 mRNA expression in 293 T cells. (C) PAR2 expression in 293T cells. (D, E) IL-6 mRNA expression in A549 cells. (F) PAR2 expression in A549 cells. GAPDH and $\beta$-actin were used as the reference housekeeping genes for internal standardization.

Additional file 2. Effect of NMB treatment on the expression of viral NP and cytokines in BMDMs. The BMDMs were mock-treated or treated with NMB after infection with PR8 $(\mathrm{MOI}=1)$. NMB-treated cells were harvested at $16 \mathrm{hpi}$. The mRNA levels of NP, IFN-a, and IL-6 were measured by RT-PCR (A). qRT-PCR measurement of NP (B), IFN- $\alpha$ (C) and IL-6 mRNA expression (D). $\beta$-Actin was used as the reference housekeeping gene for internal standardization. ${ }^{*} P<0.01$.

Additional file 3. Effect of NMBRA treatment on the expression of viral NP and cytokines in BMDMs. The BMDMs were mock-treated or treated with NMBRA after infection with PR8 $(\mathrm{MOI}=1)$. NMBRA-treated cells were harvested at 16 hpi. mRNA levels of NP, IFN- $a$, and IL-6 measured by RT-PCR (A). The expression of NP (B), IFN- $a(C)$, and IL- 6 (D) was measured by qRT-PCR. $\beta$-Actin was used as the reference housekeeping gene for internal standardization. ${ }^{* *} P<0.01$. 


\section{Additional file 4. Effect of trypsin on the expression of IL-6, PAR2} and NMBR in vitro. The BMDMs and A549 cells were infected with PR8 $(\mathrm{MOI}=1)$ in the presence or absence of trypsin. The BMDMs and A549 cells were collected at the indicated times to test the expression of IL-6 mRNA by RT-PCR and QRT-PCR and the expression of PAR2 and NMBR by Western blotting. (A, B) IL-6 mRNA expression in BMDMs. (C) PAR2 and NMBR expression in BMDMs. (D) NMBR expression in A549 cells. $\beta$-Actin was used as the reference housekeeping gene for internal standardization.

\section{Abbreviations}

BMDMs: bone marrow-derived macrophages; dpi: days post-infection; hpi: hours post-infection; IAV: influenza A virus; IFN-a/B: type I interferon; MOI: multiplicity of infection; NMB: neuromedin B; NMBR: neuromedin B receptor; NMBRA: NMBR antagonist; NP: nucleoprotein; PAR2: protease-activated receptors 2; PFU: plaque-forming unit; qRT-PCR: quantitative real-time RT-PCR; shRNA: short hairpin RNA; SPF: specific pathogen-free.

\section{Acknowledgements}

All authors would like to thank Dr. Song Wang for his contribution to this work and to thank Mogo Edit for scientific editing assistance.

\section{Authors' contributions}

$J L C$ and GY conceived and designed the study, and GY wrote the paper. GY, $\mathrm{HH}, \mathrm{MT}$ and $\mathrm{ZC}$ performed the experiments. GY and $\mathrm{HH}$ analysed and interpreted the data. $\mathrm{CH}$ and $\mathrm{BQ}$ provided critique and advice on the manuscript. JLC supervised the paper. All authors read and approved the final manuscript.

\section{Funding}

This work was supported by the National Nature Science Foundation of China (U1805231, 31602046 and 31302050), the FAFU Program for Promising Academic Youngsters (2014), and the National Key Research and Development Program of China (2016YFD0500205).

\section{Competing interests}

The authors declare that they have no competing interests.

Received: 13 May 2019 Accepted: 29 Auqust 2019

Published online: 10 October 2019

\section{References}

1. Moise NS (1985) Viral respiratory diseases. Vet Clin North Am Small Anim Pract 15:919-928

2. De Jong MD, Simmons CP, Thanh TT, Hien VM, Smith GJ, Chau TN, Hoang DM, Chau NV, Khanh TH, Dong VC, Qui PT, Cam BV, Ha DQ, Guan Y, Peiris JS, Chinh NT, Hien TT, Farrar J (2006) Fatal outcome of human influenza A $(\mathrm{H} 5 \mathrm{~N} 1)$ is associated with high viral load and hypercytokinemia. Nat Med 12:1203-1207

3. Zhou J, Wang D, Gao R, Zhao B, Song J, Qi X, Zhang Y, Shi Y, Yang L, Zhu W, Bai T, Qin K, Lan Y, Zou S, Guo J, Dong J, Dong L, Zhang Y, Wei H, Li X, Lu J, Liu L, Zhao X, Li X, Huang W, Wen L, Bo H, Xin L, Chen Y, Xu C et al (2013) Biological features of novel avian influenza A (H7N9) virus. Nature 499:500-503

4. Beigel JH, Farrar J, Han AM, Hayden FG, Hyer R, de Jong MD, Lochindarat S, Nguyen TK, Nguyen TH, Tran TH, Nicoll A, Touch S, Yuen KY, Writing Committee of the World Health Organization (WHO), Consultation on Human Influenza A/H5 (2005) Avian influenza A (H5N1) infection in humans. N Engl J Med 353:1374-1385

5. Chen Y, Liang W, Yang S, Wu N, Gao H, Sheng J, Yao H, Wo J, Fang Q, Cui D, Li Y, Yao X, Zhang Y, Wu H, Zheng S, Diao H, Xia S, Zhang Y, Chan KH, Tsoi HW, Teng JL, Song W, Wang P, Lau SY, Zheng M, Chan JF, To KK, Chen H, Li L, Yuen KY (2013) Human infections with the emerging avian influenza A H7N9 virus from wet market poultry: clinical analysis and characterization of viral genome. Lancet 381:1916-1925

6. De Clercq E (2006) Antiviral agents active against influenza A viruses. Nat Rev Drug Discov 5:1015-1025
7. Lackenby A, Thompson Cl, Democratis J (2008) The potential impact of neuraminidase inhibitor resistant influenza. Cur Opin Infect Dis. 21:626-638

8. Sheu TG, Deyde VM, Okomo-Adhiambo M, Garten RJ, Xu X, Bright RA, Butler EN, Wallis TR, Klimov Al, Gubareva LV (2008) Surveillance for neuraminidase inhibitor resistance among human influenza $A$ and $B$ viruses circulating worldwide from 2004 to 2008. Antimicrob Agents Chemother 52:3284-3292

9. Bright RA, Medina MJ, Xu X, Perez-Oronoz G, Wallis TR, Davis XM, Povinelli L, Cox NJ, Klimov AI (2005) Incidence of adamantane resistance among influenza A (H3N2) viruses isolated worldwide from 1994 to 2005: a cause for concern. Lancet 366:1175-1181

10. Deyde VM, Xu X, Bright RA, Shaw M, Smith CB, Zhang Y, Shu Y, Gubareva LV, Cox NJ, Klimov Al (2007) Surveillance of resistance to adamantanes among influenza $A(H 3 N 2)$ and $A(H 1 N 1)$ viruses isolated worldwide. J Infect Dis 196:249-257

11. Cheng PK, Leung TW, Ho EC, Leung PC, Ng AY, Lai MY, Lim WW (2009) Oseltamivir- and amantadine-resistant influenza viruses A (H1N1). Emerg Infect Dis 15:966-968

12. Dong G, Peng C, Luo J, Wang C, Han L, Wu B, Ji G, He H (2015) Adamantane-resistant influenza a viruses in the world (1902-2013): frequency and distribution of M2 gene mutations. PLoS One 10:e119115

13. Jefferson T, Demicheli V, Di Pietrantonj C, Rivetti D (2005) Amantadine and rimantadine for influenza $A$ in adults. Cochrane Database Syst Rev 2:CD001169

14. Hama R, Jones M, Okushima H, Kitao M, Noda N, Hayashi K, Sakaguchi K (2011) Oseltamivir and early deterioration leading to death: a proportional mortality study for 2009A/H1N1 influenza. Int J Risk Saf Med. 23:201-215

15. Moscona A (2009) Global transmission of oseltamivir-resistant influenza New Engl J Med 360:953-956

16. Baillie KJ, Digard P (2013) Influenza — time to target the host? N Engl J Med 369:191-193

17. Amadori M (2007) The role of IFN-alpha as homeostatic agent in the inflammatory response: a balance between danger and response? J Interferon Cytokine Res 27:181-189

18. Gough D, Messina N, Clarke CJ, Johnstone RW, Levy DE (2009) Constitutive type I interferon modulates homeostatic balance through tonic signaling. Immunity 31:166-174

19. Gajjar S, Patel BM (2017) Neuromedin: an insight into its types, receptors and therapeutic opportunities. Pharmacol rep 69:438-447

20. Ohki-Hamazaki H (2000) Neuromedin B. Prog neurobiol 62:297-312

21. Zhang WS, Fei KL, Wu MT, Wu XH, Liang QH (2012) Neuromedin B and its receptor influence the activity of myometrial primary cells in vitro through regulation of il6 expression via the Rela/p65 pathway in mice. Biol Reprod 86:154-157

22. Wang S, Chi X, Wei H, Chen Y, Chen Z, Huang S, Chen JL (2014) Influenza a virus-induced degradation of eukaryotic translation initiation factor $4 \mathrm{~b}$ contributes to viral replication by suppressing ifitm3 protein expression. J Virol 88:8375-8385

23. Li W, Gao YH, Chang M, Peng YL, Yao J, Han RW, Wang R (2009) Neuropeptide $S$ inhibits the acquisition and the expression of conditioned place preference to morphine in mice. Peptides 30:234-240

24. Gemmill ME, Eskay RL, Hall NL, Douglass LW, Castonguay TW (2003) Leptin suppresses food intake and body weight in corticosterone-replaced adrenalectomized rats. J Nutr 133:504-509

25. Yang J, Wang J, Chen K, Guo G, Xi R, Rothman PB, Whitten D, Zhang L, Huang S, Chen JL (2013) elF4B phosphorylation by Pim kinases plays a critical role in cellular transformation by Abl oncogenes. Cancer Res 73:4898-4908

26. Watanabe $Y$, Tsuchiya A, Seino S, Kawata Y, Kojima Y, Ikarashi S, Starkey Lewis PJ, Lu WY, Kikuta JC, Kawai H, Yamagiwa S, Forbes SJ, Ishii M, Terai S (2018) Mesenchymal stem cells and induced bone marrow-derived macrophages synergistically improve liver fibrosis in mice. Stem Cells Transl Med 8:271-284

27. Wang S, Zhang L, Zhang R, Chi X, Yang Z, Xie Y, Shu S, Liao Y, Chen J (2018) Identification of two residues within the NS1 of H7N9 influenza A virus that critically affect the protein stability and function. Vet Res 49:98

28. Minamino N, Sudoh T, Kangawa K, Matsuo H (1985) Neuromedins: novel smooth-muscle stimulating peptides identified in porcine spinal-cord. Peptides 6:245-248 
29. Tudor D, Riffault S, Carrat C, Lefèvre F, Bernoin M, Charley B (2001) Type I IFN modulates the immune response induced by DNA vaccination to pseudorabies virus glycoprotein C. Virology 286:197-205

30. Dénes A, Boldogkoi Z, Hornyák A, Palkovits M, Kovács KJ (2006) Attenuated pseudorabies virus-evoked rapid innate immune response in the rat brain. J Neuroimmunol 180:88-103

31. Miller LC, Zanella EL, Waters WR, Lager KM (2010) Cytokine protein expression levels in tracheobronchial lymph node homogenates of pigs infected with pseudorabies virus. Clin Vaccine Immunol 17:728-734

32. La Gruta NL, Kedzierska K, Stambas J, Doherty PC (2007) A question of self-preservation: immunopathology in influenza virus infection. Immunol Cell Biol 85:85-92

33. Wei H, Wang S, Chen Q, Chen Y, Chi X, Zhang L, Huang S, Gao GF, Chen $J \mathrm{~L}$ (2014) Suppression of interferon lambda signaling by socs-1 results in their excessive production during influenza virus infection. PLoS Pathog 10:e1003845

34. Ramirez-Garcia J, Gabriel JL, Alonso-Ayuso M, Quemada M (2015) Quantitative characterization of five cover crop species. J Agric Sc 153:1174-1185
35. Stadnyk A, Gauldie J (1991) The acute phase protein response during parasitic infection. Immunol Today 12:A7-A12

36. Taniguchi T, Takaoka A (2001) A weak signal for strong responses: interferon- alpha/beta revisited. Nat Rev Mol Cell Biol 2:378-386

37. Mitani Y, Takaoka A, Kim SH, Kato Y, Yokochi T, Tanaka N, Taniguchi T (2010) Cross talk of the interferon-alpha/beta signalling complex with gp130 for effective interleukin-6 signaling. Genes Cells 6:631-640

38. Chen Z, Luo G, Wang Q, Wang S, Chi X, Huang Y, Wei H, Wu B, Huang S, Chen $J \mathrm{~L}$ (2015) Muscovy duck reovirus infection rapidly activates host innate immune signaling and induces an effective antiviral immune response involving critical interferons. Vet Microbiol 175:232-243

\section{Publisher's Note}

Springer Nature remains neutral with regard to jurisdictional claims in published maps and institutional affiliations.
Ready to submit your research? Choose BMC and benefit from:

- fast, convenient online submission

- thorough peer review by experienced researchers in your field

- rapid publication on acceptance

- support for research data, including large and complex data types

- gold Open Access which fosters wider collaboration and increased citations

- maximum visibility for your research: over $100 \mathrm{M}$ website views per year

At BMC, research is always in progress.

Learn more biomedcentral.com/submissions 